\title{
RNA Binding Protein-Mediated Post-Transcriptional Gene Regulation in Medulloblastoma
}

\author{
Rebecca Bish*, and Christine Vogel ${ }^{\star}$
}

\begin{abstract}
Medulloblastoma, the most common malignant brain tumor in children, is a disease whose mechanisms are now beginning to be uncovered by high-throughput studies of somatic mutations, mRNA expression patterns, and epigenetic profiles of patient tumors. One emerging theme from studies that sequenced the tumor genomes of large cohorts of medulloblastoma patients is frequent mutation of RNA binding proteins. Proteins which bind multiple RNA targets can act as master regulators of gene expression at the post-transcriptional level to co-ordinate cellular processes and alter the phenotype of the cell. Identification of the target genes of RNA binding proteins may highlight essential pathways of medulloblastomagenesis that cannot be detected by study of transcriptomics alone. Furthermore, a subset of RNA binding proteins are attractive drug targets. For example, compounds that are under development as anti-viral targets due to their ability to inhibit RNA helicases could also be tested in novel approaches to medulloblastoma therapy by targeting key RNA binding proteins. In this review, we discuss a number of RNA binding proteins, including Musashi1 (MSI1), DEAD (Asp-Glu-Ala-Asp) box helicase 3 X-linked (DDX3X), DDX31, and cell division cycle and apoptosis regulator 1 (CCAR1), which play potentially critical roles in the growth and/or maintenance of medulloblastoma.
\end{abstract}

\section{INTRODUCTION}

\section{MEDULLOBLASTOMA}

Medulloblastoma, a pediatric brain tumor that arises in the cerebellum, is a devastating childhood disease. About one thousand new cases of medulloblastoma are diagnosed worldwide each year, making medulloblastoma the most common malignant pediatric brain tumor (at an incidence of 0.6 cases per 100,000 person-years) (CBTRUS 2012; Fogarty et al., 2005).

New York University, Center for Genomics and Systems Biology, New York, NY, USA

*Corresponding authors: rbish@nyu.edu (RB); cvogel@ nyu.edu (CV)

Received 14 January, 2014; accepted 17 January, 2014; published online 6 March, 2014

Keywords: medulloblastoma, pediatric cancer, RNA helicase, translation regulation
Medulloblastoma diagnoses peak in patients of 3-5 years of age, but can occur at any age, accounting for $1 \%$ of brain tumors in adults (Kaderali et al., 2009; Packer and Vezina, 2008). Medulloblastoma is treated with a combination of surgical resection, chemotherapy, and intensive radiation to the entire cerebrospinal axis (Packer and Vezina, 2008). While the overall five year recurrence-free survival rates are around $70-80 \%$, response to therapy differs dramatically depending on the exact underlying molecular alterations that drive an individual patient's tumor (Kool et al., 2012; Smoll, 2012). Different medulloblastoma subgroups, as defined by histological and/or molecular characteristics, have five year survival rates ranging from 22-95\% (Kool et al., 2012).

Beyond the poor prognosis of some medulloblastoma subtypes, the urgent need for targeted therapies for medulloblastoma is further illustrated by the extremely poor quality of life experienced by medulloblastoma survivors. Nonspecific, cytotoxic therapies cause severe neurological, endocrine, and cognitive impairments in children. One year after treatment, up to $80 \%$ of children with medulloblastoma are observed to exhibit at least one major neurological symptom such as gait problems or epilepsy (Frange et al., 2009). By identifying the molecular drivers of medulloblastoma, more precise drug targets can be pursued in hopes of increasing therapeutic efficacy and decreasing side effects. The concept of targeted drugs tailored to the specific molecular alterations present in a given tumor has revolutionized our approach to drug development. While there is still much work to be done before targeted therapeutics overtake traditional modalities, successes such as imatinib for the treatment of chronic myeloid leukemia and trastuzumab for breast cancer treatment illustrate the extraordinary potential for this strategy (Sawyers, 2004). Currently, the main obstacle to developing targeted therapy for medulloblastoma is the poor understanding of the molecular alterations underlying this disease.

In response to this need, massive effort has recently been devoted to identifying and correlating genomic and transcriptomic differences among patient tumors to understand the molecular genesis of medulloblastoma. Extensive transcriptomic analysis led to the current consensus that medulloblastoma can be divided into four tumor subgroups (Cho et al., 2011; Kool et al., 2008; Northcott et al., 2011; Remke et al., 2011; Thompson et al., 2006). Two of these subgroups, known as the Wnt and $\mathrm{SHH}$ types, are named after their known mechanism of tumorigenesis. The remaining two subtypes, which are far less well understood, are denoted Groups 3 and 4 . Studies from geneti- 
cally engineered mouse models demonstrate that these different medulloblastoma subtypes likely arise from different cell types within the cerebellum (Gibson et al., 2010; Kawauchi et al., 2012; Schüller et al., 2008; Yang et al., 2008).

Tumors driven by Wnt signaling are the least common type of medulloblastoma. Patients with Wnt-driven tumors have an excellent prognosis, with a $95-100 \%$ five year survival rate (Kool et al., 2012). Over $90 \%$ of these tumors contain a mutation in CTNNB1 ( $\beta$-catenin), which drives the activation of Wnt pathway target genes. Wnt tumors have the lowest overall mutation rate of all the medulloblastoma subtypes, and at the chromosomal level, monosomy of chromosome 6 is the only consistent alteration within this subgroup (Clifford et al., 2006).

The best-understood medulloblastoma subgroup is driven by alterations in the Sonic hedgehog (Shh) signaling pathway, comprising approximately $28 \%$ of medulloblastoma cases (Kool et al., 2012). Shh group tumors can result from somatic or germline mutation in Shh pathway genes such as SMO, PTCH1, SUFU, or GLI2 (Raffel et al., 1997; Reifenberger et al., 1998). This subtype has an intermediate prognosis. Some progress has been made in tailoring therapies specific for Shh-driven medulloblastomas, through the development of Shh pathway antagonists (Lee et al. 2012; Reifenberger et al. 1998; Yauch et al. 2009). However, the rapid development of resistance to these drugs has so far limited the usefulness of this therapeutic approach. This group of tumors was recently found to harbor frequent mutations in the promoter of telomerase reverse transcriptase (TERT), suggesting that a combination therapy with agents targeting Shh signaling and telomerase may be a promising avenue of research (Remke et al., 2013).

Group 3 tumors express genes involved in GABAergic/photoreceptor signaling, and have a poor prognosis (five year survival rates are $39 \%$ and $58 \%$ for infants and children, respectively) (Kool et al., 2012). Amplifications of the known oncogene MYC are exclusively found in Group 3, and are mutually exclusive with amplicons containing OTX2, a transcription factor that cooperates with MYC (Adamson et al., 2010; Northcott et al., 2012a). While only approximately one third of Group 3 tumors amplify MYC, these tumors have by far the worst prognosis of any medulloblastoma (Northcott et al., 2012a). Group 3 tumors were also found to be significantly enriched for mutations that are predicted to activate TGF- $\beta$ signaling (Northcott et al., 2012a). Two mouse models for MYC-amplified Group 3 tumors were recently developed, yielding an important tool for the study of these tumors (Kawauchi et al., 2012; Pei et al., 2012).

Group 4 is the most frequently observed medulloblastoma subtype comprising one third of all tumors, with an intermediate prognosis (5 year survival rate of approximately 70\%) (Kool et al., 2012). Group 4 tumors feature frequent mutation in chromatin modification genes, and express many genes involved in neuronal differentiation (Jones et al., 2012; Kool et al., 2012). Some Group 4 tumors amplify N-MYC, while the most frequent amplification (10\% of Group 4 tumors) is the duplication of synphilin-1 (SNCAIP), a protein previously implicated in neurodegenerative disease (Northcott et al., 2012a). One study suggested that NF-kB signaling may be implicated in Group 4 tumorigenesis, as several mutations were found in NF-kB pathway genes (Northcott et al., 2012a).

After transcriptomic studies firmly established that these subgroups represent four distinct disease entities falling under the umbrella of medulloblastoma, the scientific community next turned to genomic sequencing to better understand the molecular pathogenesis underlying each medulloblastoma subtype. We now have a wealth of information regarding the somatic mutations which occur in the medulloblastoma genome, thanks to major sequencing and copy number variation studies which were recently published (Jones et al., 2012; Northcott et al., 2012b; Pugh et al., 2012; Robinson et al., 2012). The implications of these massive and complex datasets are just now beginning to be understood.

One interesting observation is that many of the genes observed to be mutated in medulloblastoma are RNA binding proteins. For example, the authors of one study note that up to $15 \%$ of all medulloblastomas contain somatic mutations predicted to disrupt the function of at least one RNA helicase (Pugh et al., 2012). RNA binding proteins are especially interesting as drivers of oncogenesis because of their ability to alter the expression of large numbers of downstream genes through multiple processes: they can regulate splicing, translation efficiency, and mRNA localization, modification, and decay. In this review, we will highlight RNA-binding proteins which are known or suspected to contribute to medulloblastoma development.

\section{RNA-BINDING PROTEINS}

RNA-binding proteins are a large group of regulators (8001,000 in humans) that influence RNA processing, localization, storage, degradation, and translation efficiency (Castello et al., 2012; Glisovic et al., 2008; Wilson et al., 2009) Their combined impact is thought to account for as much as $30 \%$ of protein expression variation (Schwanhäusser et al., 2011; Vogel et al., 2010). Many RNA binding proteins regulate protein expression from a specific subset of mRNA transcripts with a related cellular function, which can be a powerful post-transcriptional mechanism to regulate cellular phenotype. RNA binding proteins often interact with the $5^{\prime}$ or $3^{\prime}$ untranslated regions (UTRs) of mRNAs, which contain a wealth of regulatory sequences that influence translational efficiency and mRNA stability (Wilkie et al., 2003). The importance of regulation of protein homeostasis by RNA binding proteins is highlighted by the numerous Mendelian genetic diseases caused by mutations in RNA binding proteins (Castello et al., 2013).

RNA binding domains can be found in a wide variety of proteins; relevant domain families include the RNA recognition motif (RRM), $\mathrm{CCCH}$ Zinc finger, Winged-helix, Ferredoxin like RNA-binding, and $\mathrm{K}$ homology domains (Lorkovic, 2012; Wilson et al., 2009). However, a number of recent studies of the mRNA-bound proteome in yeast and human cells demonstrate that many proteins without canonical RNA binding domains can also bind RNA, suggesting that we have only begun to understand this widespread and essential biochemical function (Baltz et al., 2012; Castello et al., 2012; Klass et al., 2013; Scherrer et al., 2010; Tsvetanova et al., 2010).

One family of RNA binding proteins that contains several proteins suspected to contribute to medulloblastoma tumorigenesis is the DEAD-box RNA helicase family. These proteins share a common set of domains within the helicase core, including the namesake D-E-A-D sequence in motif II (Lane, 1988). The human genome encodes approximately 30 DEAD-box RNA helicases, which metabolize ATP to unwind RNA and/or remodel RNA-protein complexes (Putnam and Jankowsky, 2013). These proteins can also clamp onto RNA, thus serving as a scaffold for the assembly of larger RNA-protein complexes (Linder and Jankowsky, 2011). RNA helicases perform a diverse variety of functions in the cell, and mutations in these genes have previously been linked to cancer (Abdelhaleem, 2004). 

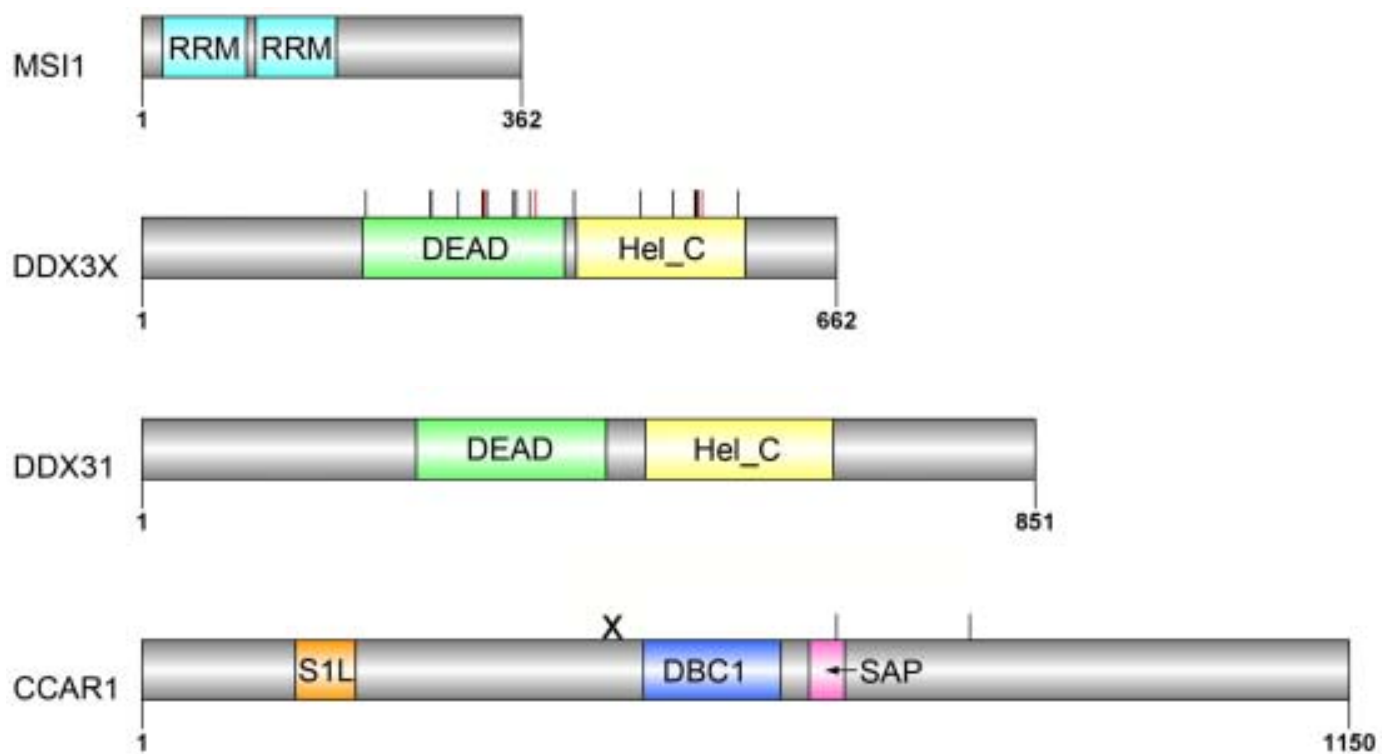

Fig. 1. Domain structures of selected RNA binding proteins. Vertical lines above the protein represent point mutations identified in medulloblastoma sequencing studies (Jones et al., 2012; Pugh et al., 2012; Robinson et al., 2012). Red lines = residues with mutations identified in multiple tumors. $X=$ truncating mutation. $R R M=R N A$ recognition motif, DEAD $=D E A D / D E A H$ box RNA helicase domain, Hel_C $=$ helicase $C$ domain, S1L = S1-like RNA binding domain, DBC1 = domain found in DBC1, SAP = SAF-A/B, Acinus and PIAS DNA/RNA binding motif. Domain annotation as predicted by InterPro (Hunter et al., 2012).

\section{MSI1}

Musashi1 (MSI1) was originally identified in Xenopus and Drosophila, and later in mammals, as an RNA binding protein essential for proper development of the nervous system (Nakamura et al., 1994; Richter et al., 1990; Sakakibara et al. 1996). MSI1 has two tandem RNA recognition motifs (Fig. 1), and functions to maintain the proliferation and renewal of multi-potent neural stem/progenitor cells. Staining for MSI1 expression can be used as a stem cell marker (Sakakibara and Okano, 1997). In addition to neural stem cells, MSI1 expression has been shown to define populations of multi-potent cells in a number of other niches, including in ducts in the breast, crypts in the intestines, and hair follicles (Kayahara et al., 2003; Sugiyama-Nakagiri et al., 2006; Wang et al., 2008). MSI1 can act as a positive or negative regulator of translation by binding to the 3'UTR of a target gene's mRNA, with an apparent preference for sequences with (G/A) $U_{1-3} A G U$ repeats (Imai et al., 2001; Vo et al., 2012). The most well-characterized function of MSI1 is enhancement of Notch pathway signaling through blocking translation of Numb, which functions to repress this pathway (Imai et al., 2001). Only a few MSI1 target mRNAs have been validated to date, including Numb, CDKN1A, doublecortin, and Robo3 (Battelli et al., 2006; Horisawa et al., 2009; Imai et al., 2001; Kuwako et al., 2010). However, recent research indicates that MSI1 regulates hundreds of targets through post-transcriptional mechanisms, affecting numerous critical cellular processes including proliferation, differentiation, and apoptosis (Sanchez-Diaz et al., 2008; Vo et al., 2012).

Medulloblastoma is considered an embryonal brain tumor as its cells resemble neural stem/progenitor cells both in general appearance and differentiation potential (Fan and Eberhart, 2008; Hambardzumyan et al., 2008). Sub-populations of stemlike medulloblastoma cells have been found within the tumor as a whole that are especially resistant to conventional therapy (Hambardzumyan et al., 2008b). The importance of MSI1 in the maintenance of neural stem cells lead to the hypothesis that MSI1 might also play a role in medulloblastoma tumorigenesis.

The first evidence for such a role came from studies showing that MSI1 is highly expressed in a number of brain tumors, including medulloblastoma (Kong et al., 2008; Nakano et al., 2007; Toda et al., 2001). Analysis of MSI1 across a large cohort of medulloblastoma samples from human patients demonstrated that high MSI1 expression is a strong indicator of poor prognosis (Vo et al., 2012). MSI1 was found to be expressed in all four medulloblastoma subtypes, with particularly high expression in Group 3 and 4 tumors (Vo et al., 2012). Another study used suppression subtractive hybridization to identify MSI1 as a gene deregulated in tumors derived from a mouse model of medulloblastoma, as compared to the normal mouse cerebellum (Yokota et al., 2004). The overexpression of MSI1 at both the mRNA and protein levels in human tumors and tumors from genetically engineered mouse models suggests that MSI1 plays an important role in medulloblastoma tumorigenesis. In medulloblastoma, MSI1 appear to exert its protumorigenic effect through overexpression of the wild-type protein, as no evidence of somatic mutations in medulloblastoma have been found to date (Forbes et al., 2011).

Evidence for a causal role of MSI1 in medulloblastoma came from studies of the widely used medulloblastoma cell line DAOY. Knockdown of MSI1 in DAOY cells diminished their ability to grow as neurospheres and to form colonies in soft agar, indicating that MSI1 helps to maintain stem cell-like properties in tumor cells (Muto et al., 2012; Sanchez-Diaz et al., 2008). Analysis of brain tumor cells in which MSI1 was knocked down resulted in impairment of several essential signaling pathways, including Notch and $\mathrm{PI}(3)$ kinase-Akt (Muto et al., 2012).

Further insight into the mechanism by which MSI1 regulates 
the growth and survival of medulloblastoma cells was provided by studies which investigated target mRNAs bound and regulated by MSI1. Reverse immunoprecipitation combined with microarray technology was used to identify genes whose mRNAs are bound by MSI1 in medulloblastoma cells (Vo et al., 2012). This list of genes was found to significantly overlap with similar experiments performed in glioblastoma cells, suggesting that MSI1 may promote tumorigenesis in a variety of tumor types. Genes regulated by MSI1 in medulloblastoma were significantly enriched for a number of cancer-related functions, including cell proliferation, apoptosis, and differentiation (Vo et al., 2012).

Proof-of-principle experiments have tested the utility of targeting MSI1 as a therapeutic measure for medulloblastoma. Treatment of mice bearing xenograft tumors derived from human medulloblastoma cell lines with siRNAs targeting MSI1 resulted in tumor regression and prolonged survival (Vo et al., 2012). Therapies that target MSI1 may also be of use for other types of cancer as well. Knockdown of MSI1 has been shown to reduce tumor size and increase overall survival in animal models of several other tumors, including glioblastoma and colorectal cancer (Muto et al. 2012; Sureban et al. 2008). Other tumors have also been shown to overexpress MSI1 in comparison to normal tissue, although the reliance of these tumors on MSI1 expression has in most cases not yet been determined (Li et al., 2011; Liu et al., 2010; Moghbeli et al., 2013; Wang et al., 2010; 2013).

\section{DDX3X}

One of the strongest emerging candidate RNA binding proteins with a potential role in medulloblastoma pathogenesis is the DEAD-box RNA helicase DDX3X. Human DDX3X was originally discovered through its interaction with proteins from the hepatitis C virus (HCV) (Owsianka and Patel, 1999). DDX3X has since been found to play contrasting roles in viral infection, being manipulated by viruses such as HCV, influenza, and human immunodeficiency virus (HIV) to facilitate viral infection (Jorba et al., 2008; Owsianka and Patel, 1999; Yedavalli et al., 2004), while also serving to activate the interferon-based innate immune response (Schroder, 2011; Soulat et al., 2008). However, anti-viral defense is only a small part of the cellular function of DDX3X. DDX3X also regulates the translation and localization of numerous mRNAs to control cellular processes that are related to cancer, including apoptosis signaling and the cell cycle (Choi and Lee, 2012; Sun et al., 2013).

Recent work has identified both general as well as specific roles of DDX3X in translation regulation. DDX3X may augment translation by resolving secondary structures of long 5 '-untranslated regions in the mRNA during ribosome scanning (Lai et al., 2008). DDX3X also binds the translation initiation factor EIF4F, allowing for translation of specific mRNAs (Soto-Rifo et al., 2012). In terms of specific targets, one study has shown that DDX3X regulates cell growth through translational control of cyclin E1 and other cell cycle regulators (Lai et al., 2010). A precise binding motif is as yet unknown, and specificity may instead result from interactions with other RNA binding proteins. On the level of general (non-targeted) translational regulation, DDX3X assists with ribosome assembly (Geissler et al., 2012).

Three recent, independent large-scale genomic sequencing studies identified frequent somatic mutations in DDX3X in medulloblastoma (Jones et al., 2012; Pugh et al., 2012; Robinson et al., 2012). In fact, DDX3X was the second-most frequently mutated gene, following only CTNNB1 (the driver mutation for Wnt pathway tumors) (Table 1). DDX3X mutations are strongly
Table 1. Most frequently mutated genes in medulloblastoma

\begin{tabular}{|c|c|c|c|}
\hline Gene & Description & \multicolumn{2}{|c|}{ \# mutations Subgroup } \\
\hline CTNNB1 & Beta-catenin & 29 & Wnt \\
\hline DDX3X & $\begin{array}{l}\text { DEAD (Asp-Glu-Ala-Asp) } \\
\text { box helicase } 3, \text { X-linked }\end{array}$ & 25 & $\begin{array}{l}\text { Wnt \& } \\
\text { Shh }\end{array}$ \\
\hline KMT2D & $\begin{array}{c}\text { Lysine (K)-specific methyltrans- } \\
\text { ferase 2D (MLL2) }\end{array}$ & 19 & all \\
\hline PTCH1 & Patched 1 & 18 & Shh \\
\hline SMARCA4 & $\begin{array}{l}\text { SWI/SNF related, matrix } \\
\text { associated, actin dependent } \\
\text { regulator of chromatin, } \\
\text { subfamily } A, \text { member } 4\end{array}$ & 18 & $\begin{array}{l}\text { Wnt, } \\
\text { Group } 3\end{array}$ \\
\hline KDM6A & $\begin{array}{l}\text { Lysine }(\mathrm{K}) \text {-specific } \\
\text { demethylase } 6 \mathrm{~A}\end{array}$ & 16 & Group 4 \\
\hline
\end{tabular}

Mutation data were tabulated from three medulloblastoma genome sequencing studies (Jones et al., 2012; Pugh et al., 2012; Robinson et al., 2012). Subgroup $=$ the subgroup(s) in which mutations most frequently occur. The top six most frequently mutated genes are listed.

enriched in the Wnt medulloblastoma subtype, with approximately half of Wnt tumors bearing a mutation in DDX3X (Pugh et al., 2012). DDX3X mutations are also seen in some Shh tumors. DDX3X mutations observed in medulloblastoma were point mutations, not truncations, and structural analysis suggests nearly all of the mutations identified occurred within the RNA helicase domain or RNA binding interface (Fig. 1) (Jones et al., 2012; Pugh et al., 2012; Robinson et al., 2012). These findings suggest that the DDX $3 X$ mutations alter the protein's function, likely in the realm of a modified protein-RNA interaction, as opposed to a complete loss of function.

To validate a potential role played by DDX3X in medulloblastoma, DDX3X was knocked down in lower rhombic lip progenitor cells, a cell population which is thought to be the cell-oforigin for Wnt-driven medulloblastomas (Gibson et al., 2010). DDX3X depletion significantly reduced the self-renewal rate of these cells, supporting the hypothesis that DDX3X promotes the development of medulloblastoma (Robinson et al., 2012).

The prevalence of DDX3X mutations in Wnt-driven medulloblastomas suggests that DDX3X mutations exert their protumorigenic effect by promoting Wnt signaling. This hypothesis is supported by the finding that co-transfection of mutant betacatenin (with an activating mutation found in $>90 \%$ of Wntdriven medulloblastomas) alongside mutant DDX3X enhanced transcription from the TOP-FLASH promoter, suggesting that these tumor-derived DDX3X mutants act to further enhance Wnt signaling in the presence of stabilized beta-catenin (Pugh et al., 2012). One recent study showed that DDX3X can play a direct role in the promotion of Wnt signaling in mammalian cells, by acting as a regulatory subunit of casein kinase 1 (CK1) (Cruciat et al., 2013). When bound to CK1, DDX3X activates phosphorylation of disheveled (DVL2), thereby promoting assembly of a multiprotein complex that results in the stabilization of betacatenin and the activation of Wnt signaling (Cruciat et al., 2013). These findings strongly support the hypothesis that the DDX3X mutations observed in medulloblastoma enhance Wnt signaling by augmenting the binding of DDX3X to CK1, thereby further enhancing the stability of mutant beta-catenin and amplifying the transcription of Wnt target genes. In this case, it appears that DDX3X exerts its regulatory effect via protein-protein, ra- 
ther than protein-mRNA interactions.

One important remaining question is the role played by the RNA binding function of DDX $3 X$ in Wnt signaling and medulloblastoma tumorigenesis. The finding that all of the DDX3X mutations are found in locations related to RNA binding suggests that alterations in the RNA binding and/or helicase function of DDX3X may contribute to the pro-tumorigenic function. Howev$\mathrm{er}$, this conjecture has to be reconciled with the finding that the promotion of Wnt signaling via CK1 is independent of both the RNA binding and ATPase activity of DDX3X (Cruciat et al., 2013). One possibility is that the RNA binding/helicase function(s) of DDX3X compete with its role as a regulator of CK1 phosphorylation. Destruction of the RNA binding capability of DDX3X may therefore free up more protein to bind CK1, thereby ultimately promoting Wnt signaling. This mechanism may involve differential localization of different pools of DDX $3 X$, depending on whether or not it is bound to RNA. However, it is also possible that the RNA binding function of DDX3X directly contributes to tumorigenesis independent of Wnt signaling, through its roles in cell cycle control, regulation of cell growth, and apoptotic signaling (Lai et al., 2010; Pek and Kai, 2011; Schroder, 2010).

\section{DDX31}

DDX31 is another DEAD-box RNA helicase that was found to be mutated in multiple tumors in a medulloblastoma sequencing study (Robinson et al., 2012). DDX31 is a protein conserved across eukaryotes, but it has not been well-studied. No DDX31-mRNA interactions have been verified for individual targets. DDX31 and its yeast homolog DBP7 participate in the transcription of rRNA genes and the assembly of the 60S ribosome subunit (Daugeron and Linder, 1998; Fukawa et al., 2012). DDX31 was characterized in humans as a nucleolar protein consistently upregulated in renal cell carcinoma (Fukawa et al., 2012). In mammalian cells, DDX31 binds nucleophosmin (NPM), blocking an interaction between NPM and HDM2, the E3 ubiquitin ligase for p53 (Fukawa et al., 2012). Depletion of DDX31 restores the NPM-HDM2 interaction, ultimately resulting in stabilization of $\mathrm{p53}$. Either of these cellular functions could plausibly contribute to a potential role for DDX31 in medulloblastoma tumorigenesis, but further study is needed.

Multiple mutations in DDX31 were observed in the medulloblastoma genome sequences. DDX31 deletions were observed in three different Group 4 medulloblastomas (as well as one tumor of unknown subtype). DDX31 was located in the breakpoint of this focal deletion, which also encompassed the genes AK8 and TSC1 (Robinson et al. 2012). The DDX31 deletions occurred simultaneously with amplification of the OTX2 locus, a known medulloblastoma oncogene (Adamson et al., 2010; Di et al., 2005). This finding suggests that DDX31 mutation (either by deletion or truncation) may cooperate with the oncogenic role of OTX2. Several other tumors in the medulloblastoma study contained DDX31 missense mutations (Robinson et al., 2012). The frequency with which DDX31 mutations occur, along with its essential functions in ribosome biogenesis and p53 regulation, suggest that DDX31 will be a fruitful target for further study of the signaling pathways involved in medulloblastoma.

\section{CCAR1}

Two of the three major medulloblastoma genome sequencing studies identified mutations in cell division cycle and apoptosis regulator 1 (CCAR1/CARP1) (Pugh et al., 2012; Robinson et al.,
2012). CCAR1 contains a cold-shock RNA binding domain, and associates with cytoplasmic RNA structures known as stress granules (Kolobova et al., 2009; Rishi et al., 2003). CCAR1 was originally discovered as a stress-induced protein that represses expression of a number of cell cycle regulatory genes, including cyclin B1 and c-Myc (Rishi et al., 2003). In addition to its role in regulation of the cell cycle, CCAR1 also mediates signaling for apoptosis (François et al., 2012; Rishi et al., 2003; 2006), and serves as a co-factor to recruit the Mediator complex to several nuclear receptors to activate transcription of downstream genes (Kim et al., 2008). The multiple mutations in the CCAR1 gene in sequencing studies and its involvement in several cancerrelated processes render the gene an excellent candidate for a potential role in medulloblastoma tumorigenesis.

Although a direct role for CCAR1 in medulloblastoma has not yet been established, one study has examined the potential of CCAR1 as a therapeutic target in medulloblastoma (Kim et al., 2008). Two human medulloblastoma cell lines were treated with small molecule inhibitors of CCAR1, known as CARP-1 Functional Mimetics (CFMs), which are designed to block the interaction of CCAR1 with the APC-2 subunit of the anaphase promoting complex (APC/C) (Puliyappadamba et al., 2011). Inhibition of CCAR 1 with the CFMs reduced cell proliferation, stimulated apoptosis, and repressed migration, colony formation, and invasion of human medulloblastoma cells (Ashour et al., 2013). These results provide further support to the hypothesis that CCAR1 may be an essential gene for the development of medulloblastoma, and an excellent target for therapeutic strategies.

\section{CONCLUSION}

Mounting evidence from studies of patient medulloblastoma samples and genetically engineered mouse models suggests that several RNA binding proteins play a role in the development of medulloblastoma.This diverse class of proteins is able to influence cellular phenotypes through both their protein-RNA and protein-protein interaction activities. Because RNA binding proteins often regulate the expression of numerous other proteins, the study of these master regulators has the potential to shed light on the pathways essential for the growth of these tumors. The identification of numerous mutations in RNA binding proteins not previously known to contribute to brain tumor pathogenesis demonstrates that there is still much work to be done in this field. As even more -omics level studies are completed, such as epigenetics (Dubuc et al., 2013) and proteomics (Epple et al., 2012) analysis, our understanding of the mechanisms of medulloblastoma tumorigenesis will be further enriched.

The RNA binding proteins described above are only few examples of the many putative regulators of medulloblastoma tumorigenesis. A large-scale cross-study analysis of aberrantly expressed RNA-binding proteins identified twelve proteins specifically up-regulated in the DAOY medulloblastoma cell line, providing candidates for further analysis (Galante et al., 2009). Among these candidates are several genes which have been linked to cancer in various capacities, including the RNA binding protein NONO/p54 (Clark et al., 1997; Schiffner et al., 2011), and the RNA helicase DHX9. ATP-dependent RNA helicases, such as DDX3X and DDX31 mentioned in this review, as well as $\mathrm{DHX9}$, are particularly interesting targets for future medulloblastoma research because of their potential as druggable targets.

Small molecule drugs aimed at inhibiting DEAD-box RNA he- 
licases are currently in various stages of development, mostly as anti-viral therapies (as RNA helicases often serve as cellular co-factors for viral infections) (Kwong et al., 2005; Lindqvist et al., 2008; Radi et al., 2012). For other RNA binding proteins, the promise of directly targeted therapies is more limited, although the discovery of small molecule inhibitors of CCAR 1 function does provide some hope. There are still significant barriers to be overcome in the development of RNAi-based therapeutics, and in the absence of other enzymatic functions, inhibitory small molecules will also likely be difficult to develop (Zhou et al., 2013). Perhaps the real promise of studying the function of RNA binding proteins in medulloblastoma lies in their role as master regulators of tumorigenic processes. By mapping the genes regulated by these RNA binding proteins, we gain tremendous insight into the pathways by which medulloblastoma cells proliferate and survive (Vo et al., 2012).

\section{ACKNOWLEDGMENTS}

The project was funded in part by the NYU University Research Challenge Fund and the NYU Whitehead Fellowship (CV).

\section{REFERENCES}

Abdelhaleem, M. (2004). Do human RNA helicases have a role in cancer? Biochim. Biophys. Acta 1704, 37-46.

Adamson, D.C., Shi, Q., Wortham, M., Northcott, P.A., Di, C., Duncan, C.G., Li, J., McLendon, R.E., Bigner, D.D., Taylor, M.D., et al. (2010). OTX2 is critical for the maintenance and progression of Shh-independent medulloblastomas. Cancer Res. 70, 181-191.

Ashour, A.E., Jamal, S., Cheryan, V.T., Muthu, M., Zoheir, K.M. Alafeefy, A.M., Abd-Allah, A.R., Levi, E., Tarca, A.L., Polin, L.A., et al. (2013). CARP-1 functional mimetics: a novel class of smal molecule inhibitors of medulloblastoma cell growth. PLoS One 8 , e66733.

Baltz, A.G., Munschauer, M., Schwanhäusser, B., Vasile, A., Murakawa, Y., Schueler, M., Youngs, N., Penfold-Brown, D., Drew, K., Milek, M., et al. (2012). The mRNA-bound proteome and its global occupancy profile on protein-coding transcripts. Mol. Cell $46,674-690$

Battelli, C., Nikopoulos, G.N., Mitchell, J.G., and Verdi, J.M. (2006). The RNA-binding protein Musashi-1 regulates neural development through the translational repression of p21WAF-1. Mol. Cell Neurosci. 31, 85-96.

Castello, A., Fischer, B., Eichelbaum, K., Horos, R., Beckmann, B.M., Strein, C., Davey, N.E., Humphreys, D.T., Preiss, T., Steinmetz, L.M., et al. (2012). Insights into RNA biology from an atlas of mammalian mRNA-binding proteins. Cell 149, 1393-1406.

Castello, A., Fischer, B., Hentze, M.W., and Preiss, T. (2013). RNAbinding proteins in Mendelian disease. Trends Genet. 29, 318327.

CBTRUS (2012). CBTRUS Statistical Report: Primary Brain and Central Nervous System Tumors Diagnosed in the United States in 2004-2008 (March 23, 2012 Revision). Hinsdale, IL, Central Brain Tumor Registry of the United States.

Cho, Y.J., Tsherniak, A., Tamayo, P., Santagata, S., Ligon, A., Greulich, H., Berhoukim, R., Amani, V., Goumnerova, L., Eberhart, C.G., et al. (2011). Integrative genomic analysis of medulloblastoma identifies a molecular subgroup that drives poor clinical outcome. J. Clin. Oncol. 29, 1424-1430.

Choi, Y.J., and Lee, S.G. (2012). The DEAD-box RNA helicase DDX3 interacts with DDX5, co-localizes with it in the cytoplasm during the G2/M phase of the cycle, and affects its shuttling during mRNP export. J. Cell Biochem. 113, 985-996.

Clark, J., Lu, Y.J., Sidhar, S.K., Parker, C., Gill, S., Smedley, D., Hamoudi, R., Linehan, W.M., Shipley, J., and Cooper, C.S. (1997) Fusion of splicing factor genes PSF and NonO (p54nrb) to the TFE3 gene in papillary renal cell carcinoma. Oncogene 15, 22332239.

Clifford, S.C., Lusher, M.E., Lindsey, J.C., Langdon, J.A., Gilbertson, R.J., Straughton, D., and Ellison, D.W. (2006). Wnt/Wingless pathway activation and chromosome 6 loss characterize a distinct molecular sub-group of medulloblastomas associated with a favorable prognosis. Cell Cycle 5, 2666-2670.

Cruciat, C.M., Dolde, C., de Groot, R.E., Ohkawara, B., Reinhard, C., Korswagen, H.C., and Niehrs, C. (2013). RNA helicase DDX3 is a regulatory subunit of casein kinase 1 in Wnt-beta-catenin signaling. Science 339, 1436-1441.

Daugeron, M.C., and Linder, P. (1998). Dbp7p, a putative ATPdependent RNA helicase from Saccharomyces cerevisiae, is required for 605 ribosomal subunit assembly. RNA 4, 566-581.

Di, C., Liao, S., Adamson, D.C., Parrett, T.J., Broderick, D.K., Shi, Q., Lengauer, C., Cummins, J.M., Velculescu, V.E., Fults, D.W et al. (2005). Identification of OTX2 as a medulloblastoma oncogene whose product can be targeted by all-trans retinoic acid. Cancer Res. 65, 919-924.

Dubuc, A.M., Remke, M., Korshunov, A., Northcott, P.A., Zhan, S.H., Mendez-Lago, M., Kool, M., Jones, D.T., Unterberger, A., Morrissy, A.S., et al. (2013). Aberrant patterns of H3K4 and H3K27 histone lysine methylation occur across subgroups in medulloblastoma. Acta Neuropathol. 125, 373-384.

Epple, L.M., Griffiths, S.G., Dechkovskaia, A.M., Dusto, N.L., White, J., Ouellette, R.J., Anchordoquy, T.J., Bemis, L.T., and Graner, M.W. (2012). Medulloblastoma exosome proteomics yield functional roles for extracellular vesicles. PLoS One 7, e42064.

Fan, X., and Eberhart, C.G. (2008). Medulloblastoma stem cells. J. Clin. Oncol. 26, 2821-2827.

Fogarty, M.P., Kessler, J.D., and Wechsler-Reya, R.J. (2005). Morphing into cancer: the role of developmental signaling pathways in brain tumor formation. J. Neurobiol. 64, 458-475.

Forbes, S.A., Bindal, N., Bamford, S., Cole, C., Kok, C.Y., Beare, D., Jia, M., Shepherd, R., Leung, K., Menzies, A., et al. (2011). COSMIC: mining complete cancer genomes in the catalogue of somatic mutations in cancer. Nucleic Acids Res. 39, D945-950.

François, S., D'Orlando, C., Fatone, T., Touvier, T., Pessina, P. Meneveri, R., and Brunelli, S. (2012). Necdin enhances myoblasts survival by facilitating the degradation of the mediator of apoptosis CCAR1/CARP1. PLoS One 7, e43335.

Frange, P., Alapetite, C., Gaboriaud, G., Bours, D., Zucker, J.M., Zerah, M., Brisse, H., Chevignard, M., Mosseri, V., Bouffet, E., et al. (2009). From childhood to adulthood: long-term outcome of medulloblastoma patients. The Institut Curie experience (19802000). J. Neurooncol. 95, 271-279.

Fukawa, T., Ono, M., Matsuo, T., Uehara, H., Miki, T., Nakamura, Y., Kanayama, H.O., and Katagiri, T. (2012). DDX31 regulates the p53-HDM2 pathway and rRNA gene transcription through its interaction with NPM1 in renal cell carcinomas. Cancer Res. 72 , 5867-5877.

Galante, P.A., Sandhu, D., de Sousa Abreu, R., Gradassi, M., Slager, N., Vogel, C., de Souza, S.J., and Penalva, L.O. (2009) A comprehensive in silico expression analysis of RNA binding proteins in normal and tumor tissue: Identification of potential players in tumor formation. RNA Biol. 6, 426-433.

Geissler, R., Golbik, R.P., and Behrens, S.E. (2012). The DEADbox helicase DDX3 supports the assembly of functional 805 ribosomes. Nucleic Acids Res. 40, 4998-5011.

Gibson, P., Tong, Y., Robinson, G., Thompson, M.C., Currle, D.S., Eden, C., Kranenburg, T.A., Hogg, T., Poppleton, H., Martin, J., et al. (2010). Subtypes of medulloblastoma have distinct developmental origins. Nature 468, 1095-1099.

Glisovic, T., Bachorik, J.L., Yong, J., and Dreyfuss, G. (2008). RNAbinding proteins and post-transcriptional gene regulation. FEBS Lett. 582, 1977-1986.

Hambardzumyan, D., Becher, O.J., and Holland, E.C. (2008a). Cancer stem cells and survival pathways. Cell Cycle 7, 1371-1378.

Hambardzumyan, D., Becher, O.J., Rosenblum, M.K., Pandolfi, P.P., Manova-Todorova, K., and Holland, E.C. (2008b). PI3K path- way regulates survival of cancer stem cells residing in the perivascular niche following radiation in medulloblastoma in vivo. Genes Dev. 22, 436-448.

Horisawa, K., Imai, T., Okano, H., and Yanagawa, H. (2009). 3'Untranslated region of doublecortin $\mathrm{MRNA}$ is a binding target of the Musashi1 RNA-binding protein. FEBS Lett. 583, 2429-2434.

Hunter, S., Jones, P., Mitchell, A., Apweiler, R., Attwood, T.K., Bateman, A., Bernard, T., Binns, D., Bork, P., Burge, S. et al. (2012). InterPro in 2011: new developments in the family and domain prediction database. Nucleic Acids Res. 40, D306-312.

Imai, T., Tokunaga, A., Yoshida, T., Hashimoto, M., Mikoshiba, K., Wein- 
master, G., Nakafuku, M., and Okano, H. (2001). The neura RNA-binding protein Musashi1 translationally regulates mammalian numb gene expression by interacting with its mRNA. Mol. Cell Biol. 21, 3888-3900.

Jones, D.T., Jäger, N., Kool, M., Zichner, T., Hutter, B., Sultan, M., Cho, Y.J., Pugh, T.J., Hovestadt, V., Stütz, A.M., et al. (2012). Dissecting the genomic complexity underlying medulloblastoma. Nature 488, 100-105.

Jorba, N., Juarez, S., Torreira, E., Gastaminza, P., Zamarreño, N., Albar, J.P., and Ortín, J. (2008). Analysis of the interaction of influenza virus polymerase complex with human cell factors. Proteomics 8, 2077-2088.

Kaderali, Z., Lamberti-Pasculli, M., and Rutka, J.T. (2009). The changing epidemiology of paediatric brain tumours: a review from the Hospital for Sick Children. Childs Nerv. Syst. 25, 787-793.

Kawauchi, D., Robinson, G., Uziel, T., Gibson, P., Rehg, J., Gao, C., Finkelstein, D., Qu, C., Pounds, S., Ellison, D.W., et al. (2012). A mouse model of the most aggressive subgroup of human medulloblastoma. Cancer Cell 21, 168-180.

Kayahara, T., Sawada, M., Takaishi, S., Fukui, H., Seno, H., Fukuzawa, H., Suzuki, K., Hiai, H., Kageyama, R., Okano, H., et al. (2003). Candidate markers for stem and early progenitor cells, Musashi-1 and Hes1, are expressed in crypt base columnar cells of mouse small intestine. FEBS Lett. 535, 131-135.

Kim, J.H., Yang, C.K., Heo, K., Roeder, R.G., An, W., and Stallcup, M.R. (2008). CCAR1, a key regulator of mediator complex recruitment to nuclear receptor transcription complexes. Mol. Cell $31,510-519$

Klass, D.M., Scheibe, M., Butter, F., Hogan, G.J., Mann, M., and Brown, P.O. (2013). Quantitative proteomic analysis reveals concurrent RNA-protein interactions and identifies new RNAbinding proteins in Saccharomyces cerevisiae. Genome Res. 23 1028-1038.

Kolobova, E., Efimov, A., Kaverina, I., Rishi, A.K., Schrader, J.W., Ham, A.J., Larocca, M.C., and Goldenring, J.R. (2009). Microtubule-dependent association of AKAP350A and CCAR1 with RNA stress granules. Exp. Cell Res. 315, 542-555.

Kong, D.S., Kim, M.H., Park, W.Y., Suh, Y.L., Lee, J.I., Park, K. Kim, J.H., and Nam, D.H. (2008). The progression of gliomas is associated with cancer stem cell phenotype. Oncol. Rep. 19, 639643.

Kool, M., Koster, J., Bunt, J., Hasselt, N.E., Lakeman, A., van Sluis, P., Troost, D., Meeteren, N.S., Caron, H.N., Cloos, J., et al. (2008) Integrated genomics identifies five medulloblastoma subtypes with distinct genetic profiles, pathway signatures and clinicopathological features. PLoS One 3, e3088.

Kool, M., Korshunov, A., Remke, M., Jones, D.T., Schlanstein, M. Northcott, P.A., Cho, Y.J., Koster, J., Schouten-van Meeteren, A., van Vuurden, D., et al. (2012). Molecular subgroups of medulloblastoma: an international meta-analysis of transcriptome, genetic aberrations, and clinical data of WNT, SHH, Group 3, and Group 4 medulloblastomas. Acta Neuropathol. 123, 473-484.

Kuwako, K., Kakumoto, K., Imai, T., Igarashi, M., Hamakubo, T., Sakakibara, S., Tessier-Lavigne, M., Okano, H.J., and Okano, H. (2010). Neural RNA-binding protein Musashi1 controls midline crossing of precerebellar neurons through posttranscriptional regulation of Robo3/Rig-1 expression. Neuron 67, 407-421.

Kwong, A.D., Rao, B.G., and Jeang, K.T. (2005). Viral and cellular RNA helicases as antiviral targets. Nat. Rev. Drug Discov. 4, 845853.

Lai, M.C., Lee, Y.H., and Tarn, W.Y. (2008). The DEAD-box RNA helicase DDX3 associates with export messenger ribonucleoproteins as well as tip-associated protein and participates in translational control. Mol. Biol. Cell 19, 3847-3858.

Lai, M.C., Chang, W.C., Shieh, S.Y., and Tarn, W.Y. (2010). DDX3 regulates cell growth through translational control of cyclin E1. Mol. Cell. Biol. 30, 5444-5453.

Lane, D. (1988). Enlarged family of putative helicases. Nature 334 478.

Lee, M.J., Hatton, B.A., Villavicencio, E.H., Khanna, P.C., Friedman, S.D., Ditzler, S., Pullar, B., Robison, K., White, K.F., Tunkey, C., et al. (2012). Hedgehog pathway inhibitor saridegib (IPI-926) increases lifespan in a mouse medulloblastoma model. Proc. Natl. Acad. Sci. USA 109, 7859-7864.

Li, D., Peng, X., Yan, D., Tang, H., Huang, F., Yang, Y., and Peng Z. (2011). Msi-1 is a predictor of survival and a novel therapeutic target in colon cancer. Ann. Surg. Oncol. 18, 2074-2083.

Linder, P., and Jankowsky, E. (2011). From unwinding to clamping the DEAD box RNA helicase family. Nat. Rev. Mol. Cell Biol. 12, 505-516.

Lindqvist, L., Oberer, M., Reibarkh, M., Cencic, R., Bordeleau, M.E, Vogt, E., Marintchev, A., Tanaka, J., Fagotto, F., Altmann, M., et al. (2008). Selective pharmacological targeting of a DEAD box RNA helicase. PLoS One 3, e1583.

Liu, D.C., Yang, Z.L., and Jiang, S. (2010). Identification of musashi-1 and ALDH1 as carcinogenesis, progression, and poor-prognosis related biomarkers for gallbladder adenocarcinoma. Cancer Biomark 8, 113-121.

Lorković, Z.J. (2012). RNA binding proteins. Austin, Tex., Landes Bioscience.

Moghbeli, M., Forghanifard, M.M., Aarabi, A., Mansourian, A., and Abbaszadegan, M.R. (2013). Clinicopathological sex- related relevance of Musashi1 mRNA expression in esophageal squamous cell carcinoma patients. Pathol. Oncol Res. [Epub ahead of print]

Muto, J., Imai, T., Ogawa, D., Nishimoto, Y., Okada, Y., Mabuchi, Y., Kawase, T., Iwanami, A., Mischel, P.S., Saya, H., et al. (2012). RNA-binding protein Musashi1 modulates glioma cell growth through the post-transcriptional regulation of Notch and $\mathrm{PI} 3$ kinase/Akt signaling pathways. PLoS One 7, e33431.

Nakamura, M., Okano, H., Blendy, J.A., and Montell, C. (1994). Musashi, a neural RNA-binding protein required for Drosophila adult external sensory organ development. Neuron 13,67-81.

Nakano, A., Kanemura, Y., Mori, K., Kodama, E., Yamamoto, A. Sakamoto, H., Nakamura, Y., Okano, H., Yamasaki, M., and Arita, N. (2007). Expression of the Neural RNA-binding protein Musashi1 in pediatric brain tumors. Pediatr. Neurosurg. 43, 279-284.

Northcott, P.A., Korshunov, A., Witt, H., Hielscher, T., Eberhart, C.G., Mack, S., Bouffet, E., Clifford, S.C., Hawkins, C.E., French, P., et al. (2011). Medulloblastoma comprises four distinct molecular variants. J. Clin. Oncol. 29, 1408-1414.

Northcott, P.A., Korshunov, A., Pfister, S.M., and Taylor, M.D. (2012a). The clinical implications of medulloblastoma subgroups. Nat. Rev. Neurol. 8, 340-351.

Northcott, P.A., Shih, D.J., Peacock, J., Garzia, L., Morrissy, A.S., Zichner, T., Stütz, A.M., Korshunov, A., Reimand, J., Schumacher, S.E., et al. (2012b). Subgroup-specific structural variation across 1,000 medulloblastoma genomes. Nature 488, 49-56.

Owsianka, A.M., and Patel, A.H. (1999). Hepatitis C virus core protein interacts with a human DEAD box protein DDX3. Virology 257, 330-340.

Packer, R.J., and Vezina, G. (2008). Management of and prognosis with medulloblastoma: therapy at a crossroads. Arch. Neurol. 65, 1419-1424.

Pei, Y., Moore, C.E., Wang, J., Tewari, A.K., Eroshkin, A., Cho, Y.J., Witt, H., Korshunov, A., Read, T.A., Sun, J.L., et al. (2012). An animal model of MYC-driven medulloblastoma. Cancer Cell 21, 155-167.

Pek, J.W., and Kai, T. (2011). DEAD-box RNA helicase Belle/DDX3 and the RNA interference pathway promote mitotic chromosome segregation. Proc. Natl. Acad. Sci. USA 108, 12007-12012.

Pugh, T.J., Weeraratne, S.D., Archer, T.C., Pomeranz Krummel, D. A., Auclair, D., Bochicchio, J., Carneiro, M.O., Carter, S.L. Cibulskis, K., Erlich, R.L., et al. (2012). Medulloblastoma exome sequencing uncovers subtype-specific somatic mutations. Nature 488, 106-110.

Puliyappadamba, V.T., Wu, W., Bevis, D., Zhang, L., Polin, L., Kilkuskie, R., Finley, R.L. Jr., Larsen, S.D., Levi, E., Miller, F.R., et al. (2011). Antagonists of anaphase-promoting complex (APC)2 -cell cycle and apoptosis regulatory protein (CARP)-1 interaction are novel regulators of cell growth and apoptosis. J. Biol. Chem. 286, 38000-38017.

Putnam, A.A., and Jankowsky, E. (2013). DEAD-box helicases as integrators of RNA, nucleotide and protein binding. Biochim. Biophys. Acta 1829, 884-893.

Radi, M., Falchi, F., Garbelli, A., Samuele, A., Bernardo, V., Paolucci, S., Baldanti, F., Schenone, S., Manetti, F., Maga, G., et al. (2012). Discovery of the first small molecule inhibitor of human DDX3 specifically designed to target the RNA binding site: towards the next generation HIV-1 inhibitors. Bioorg. Med. Chem. Lett. 22, 2094-2098.

Raffel, C., Jenkins, R.B., Frederick, L., Hebrink, D., Alderete, B., 
Fults, D.W., and James, C.D. (1997). Sporadic medulloblastomas contain PTCH mutations. Cancer Res. 57, 842-845.

Reifenberger, J., Wolter, M., Weber, R.G., Megahed, M., Ruzicka, T., Lichter, P., and Reifenberger, G. (1998). Missense mutations in $\mathrm{SMOH}$ in sporadic basal cell carcinomas of the skin and primitive neuroectodermal tumors of the central nervous system. Cancer Res. 58, 1798-1803.

Remke, M., Hielscher, T., Korshunov, A., Northcott, P.A., Bender S., Kool, M., Westermann, F., Benner, A., Cin, H., Ryzhova, M. et al. (2011). FSTL5 is a marker of poor prognosis in nonWNT/non-SHH medulloblastoma. J. Clin. Oncol. 29, 3852-3861.

Remke, M., Ramaswamy, V., Peacock, J., Shih, D.J., Koelsche, C., Northcott, P.A., Hill, N., Cavalli, F.M., Kool, M., Wang, X., et al. (2013). TERT promoter mutations are highly recurrent in $\mathrm{SHH}$ subgroup medulloblastoma. Acta Neuropathol. 126, 917-929.

Richter, K., Good, P.J., and Dawid, I.B. (1990). A developmentally regulated, nervous system-specific gene in Xenopus encodes a putative RNA-binding protein. New Biol. 2, 556-565.

Rishi, A.K., Zhang, L., Boyanapalli, M., Wali, A., Mohammad, R.M., Yu, Y., Fontana, J.A., Hatfield, J.S., Dawson, M.I., Majumdar A.P., et al. (2003). Identification and characterization of a cell cycle and apoptosis regulatory protein-1 as a novel mediator of apoptosis signaling by retinoid CD437. J. Biol. Chem. 278, 33422-33435.

Rishi, A.K., Zhang, L., Yu, Y., Jiang, Y., Nautiyal, J., Wali, A., Fontana, J.A., Levi, E., and Majumdar, A.P. (2006). Cell cycleand apoptosis-regulatory protein-1 is involved in apoptosis signaling by epidermal growth factor receptor. J. Biol. Chem. 281 , 13188-13198.

Robinson, G., Parker, M., Kranenburg, T.A., Lu, C., Chen, X., Ding, L., Phoenix, T.N., Hedlund, E., Wei, L., Zhu, X., et al. (2012). Novel mutations target distinct subgroups of medulloblastoma. Nature 488, 43-48.

Sakakibara, S., and Okano, H. (1997). Expression of neural RNAbinding proteins in the postnatal CNS: implications of their roles in neuronal and glial cell development. J. Neurosci. 17, 8300-8312.

Sakakibara, S., Imai, T., Hamaguchi, K., Okabe, M., Aruga, J., Nakajima, K., Yasutomi, D., Nagata, T., Kurihara, Y., Uesugi, S., et al. (1996). Mouse-Musashi-1, a neural RNA-binding protein highly enriched in the mammalian CNS stem cell. Dev. Biol. 176, 230-242.

Sanchez-Diaz, P.C., Burton, T.L., Burns, S.C., Hung, J.Y., and Penalva, L.O. (2008). Musashi1 modulates cell proliferation genes in the medulloblastoma cell line Daoy. BMC Cancer 8, 280.

Sawyers, C. (2004). Targeted cancer therapy. Nature 432, 294-297.

Scherrer, T., Mittal, N., Janga, S.C., and Gerber, A.P. (2010). A screen for RNA-binding proteins in yeast indicates dual functions for many enzymes. PLoS One 5, e15499.

Schiffner, S., Zimara, N., Schmid, R., and Bosserhoff, A.K. (2011). p54nrb is a new regulator of progression of malignant melanoma. Carcinogenesis 32, 1176-1182.

Schroder, M. (2010). Human DEAD-box protein 3 has multiple functions in gene regulation and cell cycle control and is a prime target for viral manipulation. Biochem. Pharmacol. 79, 297-306.

Schroder, M. (2011). Viruses and the human DEAD-box helicase DDX3: inhibition or exploitation? Biochem. Soc. Trans. 39, 679683.

Schüller, U., Heine, V.M., Mao, J., Kho, A.T., Dillon, A.K., Han, Y.G., Huillard, E., Sun, T., Ligon, A.H., Qian, Y., et al. (2008). Acquisition of granule neuron precursor identity is a critical determinant of progenitor cell competence to form Shh-induced medulloblastoma. Cancer Cell 14, 123-134.

Schwanhäusser, B., Busse, D., Li, N., Dittmar, G., Schuchhardt, J., Wolf, J., Chen, W., and Selbach, M. (2011). Global quantification of mammalian gene expression control. Nature 473, 337-342.

Smoll, N.R. (2012). Relative survival of childhood and adult medulloblastomas and primitive neuroectodermal tumors (PNETs). Cancer 118, 1313-1322.

Soto-Rifo, R., Rubilar, P.S., Limousin, T., de Breyne, S., Décimo, D., and OhImann, T. (2012). DEAD-box protein DDX3 associates with elF4F to promote translation of selected mRNAs. EMBO J. 31, 3745-3756.

Soulat, D., Bürckstümmer, T., Westermayer, S., Goncalves, A., Bauch, A., Stefanovic, A., Hantschel, O., Bennett, K.L., Decker, T., and Superti-Furga, G. (2008). The DEAD-box helicase DDX3X is a critical component of the TANK-binding kinase 1-dependent innate immune response. EMBO J. 27, 2135-2146.

Sugiyama-Nakagiri, Y., Akiyama, M., Shibata, S., Okano, H., and Shimizu, H. (2006). Expression of RNA-binding protein Musashi in hair follicle development and hair cycle progression. Am. J. Pathol. 168, 80-92.

Sun, M., Zhou, T., Jonasch, E., and Jope, R.S. (2013). DDX3 regulates DNA damage-induced apoptosis and p53 stabilization. Biochim. Biophys. Acta 1833, 1489-1497.

Sureban, S.M., May, R., George, R.J., Dieckgraefe, B.K., McLeod, H.L., Ramalingam, S., Bishnupuri, K.S., Natarajan, G., Anant, S., and Houchen, C.W. (2008). Knockdown of RNA binding protein musashi-1 leads to tumor regression in vivo. Gastroenterology 134, 1448-1458.

Thompson, M.C., Fuller, C., Hogg, T.L., Dalton, J., Finkelstein, D., Lau, C.C., Chintagumpala, M., Adesina, A., Ashley, D.M., Kellie, S.J., et al. (2006). Genomics identifies medulloblastoma subgroups that are enriched for specific genetic alterations. J. Clin. Oncol. 24, 1924-1931.

Toda, M., lizuka, Y., Yu, W., Imai, T., Ikeda, E., Yoshida, K., Kawase, T., Kawakami, Y., Okano, H., and Uyemura, K. (2001). Expression of the neural RNA-binding protein Musashi1 in human gliomas. Glia 34, 1-7.

Tsvetanova, N.G., Klass, D.M., Salzman, J., and Brown, P.O. (2010). Proteome-wide search reveals unexpected RNA-binding proteins in Saccharomyces cerevisiae. PLoS One 5, pii: e12671.

Vo, D.T., Subramaniam, D., Remke, M., Burton, T.L., Uren, P.J., Gelfond, J.A., de Sousa Abreu, R., Burns, S.C., Qiao, M., Suresh, U., et al. (2012). The RNA-binding protein Musashi1 affects medulloblastoma growth via a network of cancer-related genes and is an indicator of poor prognosis. Am. J. Pathol. 181, 17621772.

Vogel, C., Abreu Rde, S., Ko, D., Le, S.Y., Shapiro, B.A., Burns, S.C., Sandhu, D., Boutz, D.R., Marcotte, E.M., and Penalva, L.O. (2010). Sequence signatures and mRNA concentration can explain two-thirds of protein abundance variation in a human cell line. Mol. Syst. Biol. 6, 400.

Wang, X.Y., Yin, Y., Yuan, H., Sakamaki, T., Okano, H., and Glazer, R.I. (2008). Musashi1 modulates mammary progenitor cell expansion through proliferin-mediated activation of the Wnt and Notch pathways. Mol. Cell. Biol. 28, 3589-3599.

Wang, X.Y., Penalva, L.O., Yuan, H., Linnoila, R.I., Lu, J., Okano, H., and Glazer, R.I. (2010). Musashi1 regulates breast tumor cell proliferation and is a prognostic indicator of poor survival. Mol. Cancer 9, 221.

Wang, X.Y., Yu, H., Linnoila, R.I., Li, L., Li, D., Mo, B., Okano, H., Penalva, L.O., and Glazer, R.I. (2013). Musashi1 as a potential thera- peutic target and diagnostic marker for lung cancer. Oncotarget 4, 739-750.

Wilkie, G.S., Dickson, K.S., and Gray, N.K. (2003). Regulation of mRNA translation by $5^{\prime}$ - and $3^{\prime}$-UTR-binding factors. Trends Biochem. Sci. 28, 182-188.

Wilson, D., Pethica, R., Zhou, Y., Talbot, C., Vogel, C., Madera, M., Chothia, C., and Gough, J. (2009). SUPERFAMILY--sophisticated comparative genomics, data mining, visualization and phylogeny. Nucleic Acids Res. 37, D380-386.

Yang, Z.J., Ellis, T., Markant, S.L., Read, T.A., Kessler, J.D., Bourboulas, M., Schüller, U., Machold, R., Fishell, G., Rowitch, D.H., et al. (2008). Medulloblastoma can be initiated by deletion of Patched in lineage-restricted progenitors or stem cells. Cancer Cell 14, 135-145.

Yauch, R.L., Dijkgraaf, G.J., Alicke, B., Januario, T., Ahn, C.P., Holcomb, T., Pujara, K., Stinson, J., Callahan, C.A., Tang, T., et al. (2009). Smoothened mutation confers resistance to a Hedgehog pathway inhibitor in medulloblastoma. Science 326, 572-574.

Yedavalli, V.S., Neuveut, C., Chi, Y.H., Kleiman, L., and Jeang, K.T. (2004). Requirement of DDX3 DEAD box RNA helicase for HIV1 Rev-RRE export function. Cell 119, 381-392.

Yokota, N., Mainprize, T.G., Taylor, M.D., Kohata, T., Loreto, M., Ueda, S., Dura, W., Grajkowska, W., Kuo, J.S., and Rutka, J.T. (2004). Identification of differentially expressed and developmentally regulated genes in medulloblastoma using suppression subtraction hybridization. Oncogene 23, 3444-3453.

Zhou, J., Shum, K.T., Burnett, J.C., and Rossi, J.J. (2013). Nanoparticle-based delivery of RNAi therapeutics: progress and challenges. Pharmaceuticals 6, 85-107. 